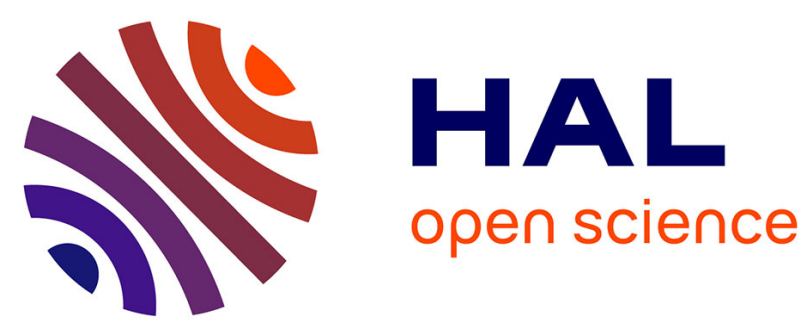

\title{
Assessing walking posture with geometric morphometrics: effects of rearing environment in pigs
}

Céline Tallet, Emilie Sénèque, Claire Mégnin, Stéphane Morisset, David

Val-Laillet, Marie-Christine Meunier-Salaün, Carole Fureix, Martine

Hausberger

\section{To cite this version:}

Céline Tallet, Emilie Sénèque, Claire Mégnin, Stéphane Morisset, David Val-Laillet, et al.. Assessing walking posture with geometric morphometrics: effects of rearing environment in pigs. Applied Animal Behaviour Science, 2016, 174, pp.32-41. 10.1016/j.applanim.2015.10.008 hal-01220634

\section{HAL Id: hal-01220634 \\ https://hal-univ-rennes1.archives-ouvertes.fr/hal-01220634}

Submitted on 27 Jan 2016

HAL is a multi-disciplinary open access archive for the deposit and dissemination of scientific research documents, whether they are published or not. The documents may come from teaching and research institutions in France or abroad, or from public or private research centers.
L'archive ouverte pluridisciplinaire HAL, est destinée au dépôt et à la diffusion de documents scientifiques de niveau recherche, publiés ou non, émanant des établissements d'enseignement et de recherche français ou étrangers, des laboratoires publics ou privés. 
Assessing walking posture with geometric morphometrics: effects of rearing environment in pigs

Céline Tallet $^{\mathrm{a}, \mathrm{b}^{*}}$, Emilie Sénèque ${ }^{\mathrm{c}}$, Claire Mégnin ${ }^{\mathrm{a}, \mathrm{b}}$, Stéphane Morisset ${ }^{\mathrm{d}}$, David Val-Laillet ${ }^{\mathrm{e}}$, Marie-Christine Meunier-Salaün ${ }^{\mathrm{a}, \mathrm{b}}$, Carole Fureix ${ }^{\mathrm{c}}$, Martine Hausberger ${ }^{\dagger}$

a INRA, UMR1348 PEGASE F-35590, Saint-Gilles, France

${ }^{\mathrm{b}}$ Agrocampus Rennes, UMR1348 PEGASE, F-35000 Rennes, France

' Université de Rennes 1, UMR CNRS 6552 Ethologie Animale et Humaine, CNRS, 35042 Rennes Cedex, France

d independent biostatistician, F-01150 Chazey sur Ain, France

e INRA, UR1341 ADNC, F-35590 Saint Gilles, France

${ }^{\dagger}$ CNRS, UMR 6552 Ethologie animale at humaine, Université de Rennes 1, 35042 Rennes Cedex, France

*corresponding author : Céline Tallet, tél: 0033 (0)2 234850 53, fax: 0033 (0)2 2348 50 80, celine.tallet@rennes.inra.fr

$\$$ present address : Carole Fureix, Centre for Behavioural Biology, Department of Clinical Veterinary Science, University of Bristol, Langford House, Langford BS40 5DU, UK 


\section{Abstract}

Rearing social animals like pigs in isolation from conspecifics can have consequences on behaviour and physiology. The aim of this experiment was to determine whether rearing conditions affect body postures. We adapted a method for quantitative evaluation of postures based on geometric morphometrics, developed in horses, for pigs and applied it in different conditions. Forty eight 75-day old females were reared either alone in $2.25 \mathrm{~m}^{2}$ pens $\left(\mathrm{IH}, \mathrm{N}=24\right.$ animals and 4 groups) or in groups of four in $4.64 \mathrm{~m}^{2}$ pens $(\mathrm{GH}, N=24)$ for two weeks. They were habituated to human handling (stroking, speaking) and marking on their backs every day, and tested individually once a day for 10 min in a corridor outside the home pen during the two subsequent weeks. We observed their behaviour and posture during the first exposure to the test (novelty), and the fourth and fifth (after habituation). On the sixth and seventh tests, a familiar stockperson was present in the corridor (human presence). Before each test, the animals were marked with seven landmarks along their length, corresponding to anatomical points and easily located. An experimenter took pictures of the animals walking along the corridor, and these pictures were transferred to tps software for analysis.

GH animals were more often active in the rearing pen than IH (median (IQ) $15 \%$ of observations [12-20\%] versus 2\% [0-13 \%]; $P<0.05$ ). All animals except one IH initiated contact with the handler during the last sessions of handling (Fisher's exact test, ns). Principal Component Analyses revealed significant effects of rearing and testing conditions on pigs' behaviour and posture. Novelty led to fewer vocalisations and more exploration for IH than $\mathrm{GH}$ animals $(P<0.05)$, but there were no differences between treatments after habituation to the testing situation. The backs of $\mathrm{IH}$ animals were more rounded than those of $\mathrm{GH}(P<0.05$; dimension 1 of PCA), independently of the test condition. Human presence had no effect on posture. 
In conclusion, the method based on geometric morphometrics that we developed to study pig posture detected variations in walking posture in pigs associated with rearing conditions. Postures might reflect affective states in pigs, as shown in other species, but further studies are needed to verify this.

\section{Keywords}

methodology, pig, posture analysis, rearing condition, welfare

We developed a quantitative method of posture assessment We compared the posture of stressed and non stressed pigs We showed that long term emotional states (mood) modify pig posture The tool is promising to assess pig and other animals'

welfare 
1. Introduction

Body posture is an important aspect of animal behaviour, and would reflect adaptation of postural tonus to the stressful situations for isntance (Kiley-Worthington, 1976). However, evaluating body posture is not simple. The simplest methods rely on visual observations by an experimenter, describing variations in the position (e.g. high/low) and/or movement of parts of the body like the ears, tail, legs or back. For instance, in dogs, posture is described according to flexion of the legs, position of the back (lowered or not), whether the dog is crouching or not (Beerda et al., 1998; Schilder and van der Borg, 2004). In stressful situations the posture is lower, with bent legs and lowered tail. Kiley-

Worthington (1976) observed that a high level of excitation may lead several species, including pigs, horses and dogs, to hold their head and tail in a high position. Visual observations seem to be simple but have some limitations, in particular that they do not allow an accurate, quantitative evaluation of the posture: for example, the back could be more or less lowered in dogs. In addition, they rely on the observer's subjective evaluation, even if precautions are taken to ensure repeatability of the method.

Quantitative methods have been developed to provide more detailed assessment. For instance, Lepicard et al. (2000) recorded the elevation of the trunk of mice from videos by measuring the distance between the trunk and a horizontal beam on which the animals walked. They showed that a greater distance confirmed an arched posture, and found postural differences between anxious and non-anxious strains of mice. In cattle, a system to describe back posture has been developed to detect lameness, using video images for analysis and calculations (Poursaberi et al., 
2010). This included the contour of the cow's back and curvature from three virtual points located at standard positions. These two studies only considered back posture, without taking into account the head's position. Another possibility is to use kinematics to characterise the geometry of movement from videos, after positioning markers at different places on the body (von Wachenfelt et al., 2009; Gregoire et al., 2013) and neck posture in horses (Lesimple et al., 2012). This approach was used recently to evaluate leg flexion of pigs for detection of lameness (Gregoire et al., 2013; Stavrakakis et al., 2014). Distances and angles between the markers can be calculated from videos to assess the shape of the animal, so the method can provide considerable quantities of information. However, the authors emphasise that it has technical challenges: it necessitates use of high quality, precisely specified materials for recording and analysing; displacement of the markers on the skin must be avoided; use of algorithms for calculations is challenging; and a large consumption of time and money is involved (Gregoire et al., 2013).

Another method has been recently developed in horses, adapting geometric morphometrics to analysis of body posture from head to tail (Deleporte et al., 2008; Fureix et al., 2011). Geometric morphometrics analyses variation in shapes and is applied in systematics, palaeontology and phylogeny. It also uses markers on the body, relies on instantaneous images (photographs or captured from videos), and can reveal subtle variations in the shape (and thus posture) of animals. In horses, it was used to discriminate behavioural postures (e.g. walking, standing) and to identify the influence of management on posture (e.g. pasture vs. individual stalls, leisure/riding lessons types of equitation...). The authors suggested that the method is promising to assess individual postures, to compare groups of animals and to contribute to welfare assessment (Fureix et al., 2011). As well as a global approach, it may also allow identification of precise aspects of posture that could be useful and should be be more thoroughly examined. For example, the global approach identified neck shape as a major issue, and a correlation between neck 
shape and back disorders was revealed (Lesimple et al., 2012). The method uses free software (tps, http://life.bio.sunysb.edu/morph/) that allows automatic calculation of the shape of animals.

In the present study we used geometric morphometrics, based on the method of Fureix et al. (2011), to assess potential variations of body posture in relation to rearing conditions in pigs, i.e. individual vs. group housing. The rearing environment influences pig behaviour and emotional state: social isolation is known to induce a high level of stress compared to group rearing, indicated by behavioural, endocrine and immune changes (Barnett et al., 1981; Herskin and Jensen, 2000; Tuchscherer et al., 2014). Isolation and group housing might therefore also affect body posture.

We also compared the posture of the pigs in different situations intended to modulate their emotional state. We compared isolation in a novel testing environment (a source of stress for pigs: Murphy et al., 2014), with the same environment after habituation, and with presence of a handler previously associated with positive interactions (a possible cause of positive states: Tallet et al., 2014).

We tested two hypotheses:

1/ Rearing animals in isolation with little space compared to rearing animals in a group with more space will produce differences in body posture. More precisely, individually housed animals could develop a rounded back associated with a low position of the head (KileyWorthington, 1976).

2/ Placing animals in different situations potentially modulating their emotional state will also produce differences in their posture. 


\section{Material and methods}

The design of the experiment was approved by the local ethics committee (Comité Rennais d'Ethique en Matière d'Expérimentation Animale, case R-2010-CT-01).

\subsection{Animals and rearing conditions}

We studied 48 75-day old female pigs (Sus scrofa domesticus) randomly allocated to two different treatments, in three independent but identical replicates (January to March 2010). They were born at the experimental unit of Saint-Gilles (INRA, France, GPS: 48.1452, -1.830114) from 30 Large White $x$ Landrace sows inseminated with Pietrain semen. Piglets were weaned at $28 \pm 2$ days of age, then spent 5 weeks in a postweaning environment and were moved to the finishing building for the experiment at 75 days of age. In the finishing room, the temperature was automatically set at $22^{\circ} \mathrm{C}$. The animals had ad libitum access to food (standard fattening diet, Cooperl Arc Atlantique, Plestan, France) and water and troughs were replenished every morning (around 08:00h).

The two treatments were variations in the social and spatial housing conditions. Individually-housed $(I H)$ animals $(\mathrm{N}=24)$ were reared alone in $2.25 \mathrm{~m}^{2}$ pens $(0.85 \times 2.65 \mathrm{~m})$. Pens were separated by opaque walls. Animals could not see each other but could hear and smell their conspecifics. Group-housed $(G H)$ animals ( $N=24$ individuals in 6 pens) were reared in groups of four in $4.64 \mathrm{~m}^{2}$ pens $\left(1.75 \times 2.65 \mathrm{~m}, 1.16 \mathrm{~m}{ }^{2} \quad\right.$ per animal). All the animals were reared in the same room. The mean weight of $\mathrm{IH}$ animals was $31.5 \mathrm{~kg} \pm 0.3$ and that of $\mathrm{GH}$ animals was 32.6 0.4 at the start of the experiment. 


\subsection{Familiarisation to human handling}

Morphometrics necessitates handling the animals to place landmarks, so all pigs were first habituated to handling. Pigs received 14 sessions of handling over a period of two weeks (D1 to D12, excluding week-ends, Table 1). During the first week, they received 2 sessions per day (08:30 and 13:30 $\mathrm{h}$, excluding the first morning when they were transferred to the finishing building). During the second week, sessions occurred once per day $(08: 30 \mathrm{~h})$. Troughs were replenished $1 \mathrm{~h}$ before the sessions.

In the familiarisation sessions the handler stood motionless at the entrance of the pen for $30 \mathrm{~s}$, then sat on a bucket for $30 \mathrm{~s}$ (IH animals) or 1 min ( $\mathrm{GH}$ animals); the duration was longer for $\mathrm{GH}$ animals to allow for the larger space available and make sure that all animals had time to access the handler. Finally he/she interacted with each animal for 2 min, using a process adapted from Tallet et al. (2014). First, the handler held out a hand towards the animal. If the pig did not move away, the handler tried to touch it. If it accepted being touched, the handler softly stroked the body from head to back with the palm of the hand. If it accepted this, it was stroked with two hands. During the second week, the last minute of contact was modified to habituate the pig to being marked, simulating marking by pressing a marker on its back in different locations, from head to tail. Handling sessions were performed by three stockmen wearing green overalls and boots, and three female students wearing blue or grey overalls and boots, so that the animals were used to being handled by different people. All animals received handling from

six people. 
During each session, the handler observed the reactions of the animals. When they entered the pen, it was noted whether each animal approached within $50 \mathrm{~cm}$. During handling, the handler noted whether each animal accepted being touched without signs of avoidance (squealing, moving back). When they left the pen, they noted whether each animal followed, with its head less than $30 \mathrm{~cm}$ away. We calculated the number of animals expressing each of these behaviours per treatment for each session.

\subsection{General activity in the rearing pen}

To determine the effect of housing conditions, we recorded behaviour during $2 \mathrm{~h}$ (11:00 to 13:00 h) on a Saturday (Day 20, Table 1), when there was no human disturbance after animals were fed in the early morning. Cameras (Panasonic, PC25-2230P, Japan) were fitted above the pens, linked to a multiplexor (Advanced Technology Video, DPX9, Washington, USA) and a recorder (Panasonic, AG-TL500, Japan). Videos were analysed with The Observer XT 9.0 (Noldus, Netherlands). Scan samples were taken every 5 min, giving 25 observations per animal. Two categories of behaviour were observed: position (standing, sitting, lying) and activity (feeding, drinking, exploring the pen). Social interactions of GH animals were also observed (including sniffing, nibbling, licking). It was not possible to see all animals in every scan (e.g. the view was sometimes blocked by another animal), and overall we missed an average of 2 (range 1- 4) scans per pig. We calculated the number of times observed in each behaviour as a proportion of the number of scans obtained.

2.4. Behaviour and posture expressed in isolation and during human presence

General test conditions 
Behaviour (from video records) and posture (from photographs) were observed during three different test conditions: in a novel environment (novel condition), after habituation to the novel situation (habituation condition) and in the presence of a human (human interaction condition). All these situations were obtained in the same experimental corridor (Figure 1) and all animals were subjected to this test the same number of times. We proceeded differently for $\mathrm{GH}$ and $\mathrm{IH}$ animals. To test $\mathrm{GH}$ animals, the whole group was first moved to a waiting area (Figure 1) by a stockperson who was involved in handling sessions. From this area, one pig was selected and put into the starting zone of the corridor for the test. Each pig was tested and then the group was led back to the home pen. $\mathrm{IH}$ animals were directly moved from their home pen to the starting zone by the same stockperson as $\mathrm{GH}$ animals.

In the starting zone, the same familiar stockperson marked the animals at different points along the body (left and right side) with a non-toxic on

blue marker, to analyse their posture (see description below). After marking, the stockperson opened the door so that the tested animal was free to explore a $4.2 \mathrm{~m}$ corridor for $10 \mathrm{~min}$. The corridor was wide enough $(0.62 \mathrm{~m})$ that the animals could turn back. The outer wall of the corridor was of Plexiglas ${ }^{\circ}$ so that videos and photographs could be taken. The inner wall was opaque so that GH test animals could not see their group or vice versa, but could hear and smell them.

Videos were obtained with a video camera (Sony, HDR-XR200VE) on a stand. The behaviour was subsequently analysed by one trained experimenter using handheld computers (Psion WorkAbout ProG2) equipped with Pocket Observer (Noldus, Netherlands). Pictures of the profile of the animals were taken with a camera (Canon 1000 EOSD, 50mm objective, Japan) by another experimenter. We only considered animals walking and excluded those standing because this was uncommon. 


\section{Positioning of the landmarks}

Six landmarks (solid circles, diameter $3 \mathrm{~cm}$ ) were drawn on each side of the pig's body with a marker pen, with the eye as a seventh landmark (Figure 2):
1: Above the corner of the lip
2: Eye
3: Flat zone behind the ear
4: Head of the scapulum (shoulder)
5: Twelfth dorsal vertebra
6: End of the furrow of the thigh
7: Base of the tail

These were chosen because they corresponded to anatomical points, were easy to locate. They were put by trained experimenters on each side of the animals, so that they were visible regardless of the direction in which the animal was walking.

Responses to novelty and habituation

Each animal was subjected to the situation once a day from D15 to 19. The first session (D15) was novel, while by the fourth and fifth sessions (D18-19) the animals will have been at least partly habituated to the situation. 
Behavioural observations were performed by one person, and consisted of continuous sampling for: •

Motor activity, including:

o Sniffing ${ }^{1}$ the floor or walls: snout less than $5 \mathrm{~cm}$ from the substrate,

o Nibbling the pen: taking part of the pen in the mouth,

o Licking the floor or walls,

o Lying $^{1}$ down without exploratory activity.

o Locomotion ${ }^{1}$, noting the position of the animal in one of four zones (Figure 1), the zone in which its front legs were, and recording the number of zones entered during the test.

- Vocalisations ${ }^{1}$, divided into two categories (Reimert et al., 2013; Tallet et al., 2013).

o Low-pitched vocalisations, i.e. grunts,

o High-pitched vocalisations, i.e. squeals, grunt-squeals, screams, usually in response to stress or pain.

The experimenter had been trained to discriminate these categories during a pre-experiment. Data were transferred to The Observer XT 9.0

(Noldus, Netherlands) for calculation of the duration of each activity, the number of zones entered and the number of vocalisations of each type.

Response to human presence

${ }^{1}$ We used definitions from the ontology ATOL: http://www.atol-ontology.com/index.php/en/ 
On D22 and 23 (Table 1), animals were moved again to the testing pen where an experimenter was present. The experimenter was a stockperson who handled the tested pigs during the first two weeks of the experiment for familiarisation, and was in charge of their daily care (feeding, cleaning). He wore the same overalls as during the familiarisation sessions in the home pen. He sat at the far end of the corridor from the start, and kept this position for $2 \mathrm{~min}$. The total time the animals spent in contact with the experimenter was recorded, including sniffing, nibbling or jumping on him. Then, the experimenter walked along the corridor several times (5-10 times, depending on the animals' willingness follow him), so that we could take photographs of their walking posture. The test lasted either until the animals stopped following or a maximum of $10 \mathrm{~min}$ had elapsed.

\subsection{Preparation of the photographs and shape description}

Two landmarks could not be used: Landmark 1 because its position was not homogeneous due to movements of the pigs; Landmark 3 because it was often hidden behind the ear. We selected 1083 photographs that fitted two criteria. The animal had to be perpendicular to the camera, with the five remaining landmarks visible. Pictures of an animal moving to the right were reversed horizontally so that in all pictures the head of the pig was on the left. Shape was then described using Tps software (http://life.bio.sunysb.edu/morph/) following the method of Fureix et al. Landmarks were digitised by one trained experimenter via "tpsDig2" positioning the landmarks on a grid to obtain their coordinates. Landmarks were digitised by one trained experimenter via "tpsDig2" positioning the landmarks on a grid to obtain their coordinates. were loaded into "tpsUtil" to define the links between landmarks and create the shape, and the links file saved. Finally, the data were Generalised Procrustes Analysis (GPA) using R (version 3.0.1, The R Foundation for Statistical Computing, http://www.rfoundation/). GPA allows comparisons of shapes after filtering out effects of location in space, rotation and scale (for more statistical Then files analysed by Zelditch et al., 2004). Zelditch et al. (2004) explained the rationale and applications of GM methods in detail, so we only summarise project.org/ details, see 
below a basic principle. The theory of shape underlying GM (Kendall, 1986) enables a clear distinction between the notions of shape and of scale (size): two objects of different size are considered similar in shape when they appear identical after filtering out effects of location in space, rotation and scale. Superimposition methods (e.g. with generalized least squares Procrustes superimposition) eliminate non-shape variation in configurations of landmarks by iteratively translating, rescaling them in a common size, and optimally rotating to minimize the squared differences between corresponding landmarks. This means in our case that shapes of living individuals differing in size (e.g. because of inter-individual variation in body conditions, or if the pictures were taken from slightly different distances) can be compared easily.

\subsection{Statistical analysis}

We could not obtain any good pictures for one $\mathrm{IH}$ animal because it did not walk into the test corridor and it was therefore excluded from all analyses. Behaviour in the home pen is presented with descriptive statistics: medians and quartiles are reported.

Data were analysed with R (version 3.0.1), with the 'geomorph' library for GPA, Ime4 and predict-means library for ANOVA. Normality was tested with the Shapiro-Wilk test, and statistical analyses adapted to the results; ANOVA for normally distributed data and Mann-Whitney $U$ test for non-normally distributed data. In the rearing pen, we tested the effect of housing condition on the number of animals expressing each reaction to human handling (e.g. approaching when the experimenter entered the pen) by Fisher's exact test. The effect of housing conditions behaviour in the rearing pen and time spent in contact with the experimenter in the test corridor was analysed by Mann-Whitney $U$ test. 
Behaviour in test conditions novel and habituation was analysed with a Principal Components Analysis (PCA) followed by mixed ANOVA on the coordinates of each individual for each condition on the PCA's first two dimensions. The model included the effect of housing condition, test condition and their interaction, and the individuals as random factor. For the post-hoc comparisons P values were corrected with Tukey's method.

Shape was analysed with a PCA on the GPA coordinates. For the first two dimensions of the PCA, the median and interquartile (IQ) of the coordinates of each individual in each test condition were then calculated. Mixed ANOVA was then performed on these data. The model was similar to the one used for behaviour. This procedure was repeated twice, first by including only novel and habituation conditions, to have results comparable with behaviour, and second by including all three test conditions.

Shape during condition Hum was then analysed separately in the same way (PCA and post analysis), to test the effect of the time spent interacting with the human on posture. Taking into account the continuous distribution of the values from 27 to $105 \mathrm{~s}$, we decided to compare the animals that spent a longer time in contact with the experimenter (above the third quartile, $90.6 \mathrm{~s}$ ) to those that spent a shorter time in contact (below the first quartile, $51.7 \mathrm{~s}$ ). This included 9 animals in each category, $5 \mathrm{IH}$ and $4 \mathrm{GH}$ in each. The effects of housing condition and the time spent interacting with the experimenter in the test (low versus high) were then calculated with Mann-Whitney tests.

3. Results

\subsection{Pre-test observations}


3.1.1. General activity in the rearing pen

The animals spent most of the time lying (GH 73\%, range 67-81, IH 87\%, 72-94, Mann-Whitney $U=43.5, P=0.18$ ). IH animals spent less time standing $(12 \%, 5-22$ versus $26 \%, 19-32 ; U=107.5, P=0.04)$ and exploring than $\mathrm{GH}(2 \%, 0-13$ versus $15 \%, 12-20, U=108.5, P=0.03)$. There was no difference in time eating/drinking (8\%, 4-14 for both, $U=69, P=1)$. GH animals spent $3 \%(2-3)$ of their time in social interactions.

3.1.2. Familiarisation to human handling

In the first familiarisation session almost no animals, from either rearing system, approached the human when he/she entered the pen (Fisher test, $P=0.49$, Figure 3a), kept in contact during the session $(P=1$, Figure $3 b)$ or followed the experimenter when he/she left the pen $(P=0.61$, Figure 3c). The number of animals attracted by the experimenters increased over successive sessions, slightly faster for GH animals. More GH animals approached the human when they entered, between sessions 5 and 9 (Figure $3 a)$. From session 7 all $\mathrm{GH}$ animals did so (GH vs $\mathrm{IH}$ : $P$ 0.002), and kept contact during the session (GH vs IH: $P=0.0497$, Figure 3b), and from session 8 all $\mathrm{GH}$ animals followed the experimenter when they left the pen ( $\mathrm{GH}$ vs IH: $P=0.02$, Figure $3 \mathrm{c})$. There was no significant difference between $\mathrm{GH}$ and $\mathrm{IH}$ from session 10 , in their

response when the experimenter entered $(P=0.49$, Figure 3a), from session 8 during the session $(P=0.11$, Figure 3b), and from session 10 when the experimenter left $(P=0.23$, Figure $3 c)$. In the last session, all animals except one IH approached the experimenter throughout, so there was no difference between treatments $(P=0.49)$. 


\subsection{Observations during the tests}

\subsubsection{Behaviour and posture in novel and habituation conditions}

Behaviour

The first two dimensions of the PCA contributed $49 \%$ of the total variance $(27.2 \%$ and $21.9 \%$ respectively, 1.9 and 1.5 respectively for the eigenvalues, Figure 4). The first dimension, which could reflect the level of comfort, represented exploration (left hand side of the axis) and vocalisations (right hand side of the axis). The second dimension reflects "movement" and opposed lying (negative value) to physical activity (nibbling, locomotion). Vocalisations were mostly low-pitched $(96 \% \pm 1)$. ANOVAs on the coordinates of the animal showed significant interactions between housing and testing conditions (dimension 1: $F_{(1 / 45)}=8.3, P=0.006$; dimension 2: $F_{(1 / 45)}=4.76, P=0.03$ ). In the novel environment, $\mathrm{IH}$ explored significantly more than $\mathrm{GH}$ animals (dimension 1 , negative values, $P=0.002$ ). They also tended to move more (dimension 2, $P=0.099$ ) than $\mathrm{GH}$. After habituation $\mathrm{GH}$ animals explored significantly more than in novel condition (dimension 1 , negative values, $P<0.0001$ ) while there was no effect of the testing condition for $\mathrm{IH}$ animals (dimension $1, P=0.61$ ). However $\mathrm{IH}$ animals moved significantly less after habituation than before (dimension 2, $P=0.001)$, while there was no effect of testing condition for $\mathrm{GH}$ individuals $(P=$ 0.90). In condition habituation, $\mathrm{IH}$ and $\mathrm{GH}$ animals did not differ on either dimension $1(P=0.93)$ or $2(P=0.99)$.

\section{Posture}

After selection, we obtained 13 (quartiles 10-28) pictures per animal. The PCA performed on the GPA coordinates of pictures from each individual during novel and habituation conditions is presented in Figure 5. The first two dimensions contributed 33\% of the total variance (17.0\% and $16.2 \%$ respectively; 1.2 and 1.1 respectively for the eigenvalues. On the first dimension the left hand side was characterised by 
rounded back (minimum) while the right hand side was characterised by a flat back (maximum, Figure 5b). On the second dimension the most negative values were characterised by a stretched back between scapula (landmark 4) and twelfth dorsal vertebra (landmark 5) while the most positive values were characterised by a more contracted back (maximum, Figure 5c).

ANOVAs on individuals' coordinates showed no significant interaction between the housing and testing conditions (Figure 5a). The housing conditions had a significant influence on the median of dimension $1\left(F_{(1 / 45)}=5.43, P=0.02\right)$ : The backs of $\mathrm{IH}$ animals were rounder $(-0.14 \pm$ $0.12, N=40)$ than those of $\mathrm{GH}(0.24 \pm 0.09, N=47)$, but there was no effect of housing conditions on dimension $2(\mathrm{IH} 0.06 \pm 0.12, \mathrm{GH} 0.07 \pm$ $\left.0.11, F_{(1 / 45)}=0.33, P=0.57\right)$ or on the variability on either dimension $(P>0.10)$. Variability $(I Q)$ of dimension 1 was higher for habituation $(1.37 \pm$ $0.10, N=46)$ than for novel condition $\left(0.83 \pm 0.09 ; F_{(1 / 38)}=15.53, P<0.001, N=41\right)$, but there was no effect of testing condition on dimension $\left(1.17 \pm 0.07\right.$ versus $\left.1.05 \pm 0.54 ; F_{(1 / 38)}=1.06, P=0.31\right)$ or on the median of either dimension $(P>0.10)$.

\subsubsection{Behaviour and posture during human presence}

There was no effect of rearing condition on time spent in contact with the experimenter in the testing area (median $78 \mathrm{~s}[52-91 \mathrm{~s}], U=163, P=$ 0.94). All animals except two GH spent more than one third of their time in contact. After selection, we obtained 7 (3-26) pictures per animal during the 'human condition', Hum. The first two dimensions of the PCA contributed 35\% of the total variance (19.4\% and $15.9 \%$ respectively, 1.4 and 1.1 respectively for the eigenvalues, Figure 6). Distortions explaining the positive and negative values of the two dimensions are similar those derived from the PCA on postures during novel and habituation conditions.

There was no effect of rearing condition on the posture of the animals $(U<293, P>0.24)$, nor any association of time spent near the experimenter (first vs. third quartiles) with posture $(U<52, P>0.34, N=9$ for each quartile category). 


\subsubsection{Comparison of shape between test conditions}

In addition, we compared shape in conditions novel, human interaction and habituation. The first two dimensions of the PCA contributed 39\% of the total variance $(14.6 \%$ and $14.5 \%$ respectively; 1.0 and 1.0 respectively for the eigenvalues). The distortions carried by the two dimensions were again similar to the other PCA. There was no significant effect of test condition on medians of dimensions 1 and 2 , nor on variability in dimension $2(F<2.78, P>0.05)$. Variability in dimension 1 was higher in habituation $(1.24 \pm 0.10)$ than in novel (0.82 \pm 0.10$)$ or human interaction condition $\left(0.92 \pm 0.10 ; F_{(2 / 80)}=5.80, P=0.004\right) . \mathrm{IH}$ animals had more rounded backs than $\mathrm{GH}$ (median on dimension $1 ; F_{(1 / 45)}=4.59, \quad P$ $=0.04)$ whatever the situation

\section{Discussion}

Influence of housing conditions on behaviour and posture

We found clear differences between group-housed and individually-housed pigs, both in their rearing environment (behaviour), and in the testing pen (posture and behaviour). Individually-housed pigs were less active than group-housed pigs in their home pen (14\% vs. 41\% of observations). This may suggest that individually-housed animals had developed apathy due to stress (Fureix et al., 2012). It occurred even though human presence linked to the experimental procedure may have been perceived as an enrichment by the pigs, and thus may have rendered the situation less stressful. The differences of activity may be explained by the social and spatial environment. There may have been a 
social facilitation of activity, animals from the group no-being independent in terms of movements. Social deprivation is known to induce the chronic stress reaction of increased cortisol (Barnett et al., 1981; Tuchscherer et al., 2014). Even though social deprivation was partial in our experiment, as individually-housed animals could hear and smell each other, these pigs were potentially stressed by their rearing conditions. The space allowance may also have modulated their general activity. On the one hand, individually-housed pigs had more space per animal (2.3 vs $1.2 \mathrm{~m}^{2}$ ), which might be expected to result in higher exploration and general activity (Vermeer et al., 2014), whereas activity was actually lower. On the other hand, individually-housed animals had only $2.3 \mathrm{~m}^{2}$ in total while group housing provided $4.6 \mathrm{~m}^{2}$. The ambiguous effects of relative space per pig and absolute space per pen have previously been emphasised by Hörning (2007).

We also measured the consequences of social and spatial deprivation on posture. Individually-housed animals had more rounded backs than ondions, withol group-housed animals while walking in all test conditions, without interaction between housing and test condition. Beerda et al. (1999) showed that individually-housed dogs express lower postures when compared to group-housed, with rounder backs, and that this was a consequence of stress (Beerda et al., 1999). Similarly, a rounded back associated with a low position of the head has been described during negative situations in pigs (Kiley-Worthington, 1976), such as pain, sickness and fear. We may thus hypothesise that individual housing of pigs is associated with stress or other negative emotions. To confirm the hypothesis, the internal state of pigs will have to be measured by cortisol assay, or behavioural tests like elevated plus maze or cognitive bias (Murphy et al, 2014) will have to be used. This rounded posture seems to be adaptive for the animals, as a high elevation of the trunk would be associated with an increase of postural tonus (Kiley-Worthington, 1976) and would allow faster, easier mobilisation of the limbs to escape a stressful situation (Lepicard et al., 2003). An alternative hypothesis is that limited locomotor activity of individually-housed pigs may have modified their musculo-skeletal system and gait. Indeed, confinement of swine for long 
periods has been reported to affect the incidence and severity of structural leg weakness, with potential effects on gait and/or body posture (2 months: Sather and Fredeen, 1982; all gestation: Schrenck et al., 2008). However, in our experiment space reduction without walking lasted only for two weeks, which seems too short to have such strong consequences on gait. These results should be checked by measuring posture before the experimental conditions are applied, to be sure that there are no conformation differences before the experiment, even though we used only females of the same breed reared in the same conditions so that conformation differences were unlikely.

The method we developed was sensitive to variation in posture related to daily living conditions. In horses, this approach has enabled focus on key components of posture that reflect physical problems and altered welfare (Lesimple et al., 2012). Applications to pig welfare therefore seem possible, while requiring further validation.

\section{Postural changes with test conditions}

We compared behaviour and posture of pigs subjected for the first time to an individual test outside the home pen (novelty), and after four repetitions of the test (habituation). Group-housed pigs were also separated from their penmates for the first time, while individually-housed pigs were used to social isolation. Correspondingly, isolation in the test had different effects. Group-housed individuals explored less and reacted mostly by vocalising (PCA dimension 1), and moved less (PCA dimension 2) than individually-housed pigs. We interpreted this as showing that they were less comfortable. Individually-housed pigs explored the corridor more and moved more. Low and high-pitched vocalisations were correlated to each other, but not to motor activity. Isolation is known to induce different types of vocalisations (Weary et al., 1997; Tallet et al., 2013), reflecting different emotional or motivational states, e.g. seeking for social contact, stress. Group-housed animals were thus apparently 
stressed by the situation. Individually-housed animals would have been less stressed by the situation, and thus started to explore the pen (sniffing, nibbling, licking) from the first test (PCA dimension 1). After four tests, there were no longer behavioural differences between groups. Motor activity and vocalisations were lower, and exploration higher than for the first test. These are expressions of habituation (Kanitz et al., 2014). These behavioural data confirm that we were able to compare posture in situations with different meanings for pigs. There was no effect the test situation, nor interaction between the situation and rearing condition, on posture. The only difference was an increase after habituation in variability of dimension 1 of the PCA (roundness of the back). This variability increased again during human presence. This variability may be linked to individual differences in posture - we did not study these, but they have been observed in horses (Fureix et al., 2011) - or in perception of the situations. Variability did not reflect differences in the size of the animals (procrustes analyses were done to make the animals comparable). The higher level of arousal in the two other conditions may have decreased these individual effects.

Posture is modified by negative situations like pain and fear in pigs (Kiley-Worthington, 1976), rats (Lepicard et al., 2000) and dogs (Beerda et al., 1998). The fact that our isolation test did not affect pigs' posture may result from methodological issues. For example, changes in posture might have been too detailed to be detected using only five landmarks. Fureix et al. (2011) used eight landmarks in horses. It might be worthwhile to use more landmarks in pigs, as we unsuccessfully tried to do. One possible solution to this problem could be to describe the outline of the body rather than using landmarks, a method currently under development (Sénèque, personal communication). We may also have missed some information by studying walking posture. Fureix et al. (2011) studied standing posture, when horses were either motionless or observing the environment. We focused on walking because our pigs were rarely observed standing, only in $11 \%$ of pictures. However, walking involves movements that may modify posture sufficiently to obscure variations due to stress. Moreover, pictures were not all taken at the same 
stage of the pace, introducing additional variability, although taking many pictures for each animal and studying the median posture will have decreased the importance of this. It remains true that the situation may not have been negative enough (especially for individually-housed pigs) induce postural changes, even if it was sufficient to induce behavioural changes.

Finally, we wanted to determine whether posture varied in the presence of a familiar handler. Most animals spent more than one third of their time in contact with the stockperson in the test pen. This person was thus attractive and the situation was probably considered as positive by the animals (Tallet et al., 2014). We found no significant effect of this situation (subject again to the methodological limits described above). While Kiley-Worthington (1976) reported postural variation between animals showing greetings and fear, for instance, differences between negative and positive situations were not clear in her study. Similar postures were induced by frustration or greetings, and by aggressiveness or threat. Despite their recognition as crucial for good welfare, little is known about positive affective states in almost all animal species (Boissy et al., 2007), and the influence of positive states on animals' posture needs further investigation.

Furthermore, the amount of contact with the human did not influence posture. A major factor may have been that almost all animals approached the stockperson rather than showing fear. Variation in the positivity of the event may have been too low to be detected by our method. One way increase differences might been to test responses to an unknown human.

\section{Conclusion}


The method based on geometric morphometrics that we developed to study pig posture detected differences in walking posture between pigs housed with different socio-spatial criteria. Individually-housed animals adopted a rounder back outside the home pen. This is in line with studies in other species, showing associations between this posture and negative, stressful conditions. However, we could not detect any influence of different test conditions on posture, evaluated outside the home pen. This may indicate a need for methodological improvements, to detect more subtle variation in body posture, and potentially to study the impact on posture of emotions.

\section{Acknowledgements}

This project was partially funded by a grant from Rennes 1 University (Projets émergents) and was made possible thanks to scientific meetings of the GIS CCS (Groupement d'Intérêt Scientifique, Cerveau-Comportement-Société). The authors are grateful to Patrice Roger, Jérémy Rissel, Vincent Piedvache, Fabien Guérin, Kardiatou Sy, Carole Guérin, Michel Lefèbvre and Sylvie Guérin for their participation in different phases of the experiment. We thank the ISAE and Mike Appleby, who kindly edited for readability and for correct English the revised manuscript.

\section{References}

Barnett, J.L., Cronin, G.M., Winfield, C.G., 1981. The effects of individual and group penning of pigs on total and free plasma corticosteroids and the maximum corticosteroid binding-capacity. Gen. Comp. Endocrinol. 44, 219-225.

Beerda, B., Schilder, M.B.H., van Hooff, J.A.R.A.M., de Vries, H.W., Mol, J.A., 1998. Behavioural, saliva cortisol and heart rate responses to different types of stimuli in dogs. App. Anim. Behav. Sci. 58, 365-381. 
Beerda, B., Schilder, M.B.H., Van Hooff, J.A.R.A.M., De Vries, H.W., Mol, J.A., 1999. Chronic Stress in Dogs Subjected to Social and Spatial Restriction. I. Behavioral Responses. Physiol. Behav. 66, 233-242.

Boissy, A., Manteuffel, G., Jensen, M.B., Moe, R.O., Spruijt, B., Keeling, L.J., Winckler, C., Forkman, B., Dimitrov, I., Langbein, J., Bakken, M., Veissier, I., Aubert, A., 2007. Assessment of positive emotions in animals to improve their welfare. Physiol. Behav. 92, 375-397.

Deleporte, P., Sénèque, E., Fureix, C., Richard, J.-P., Henry, L., Biquand, V., 2008. Morphométrie et comportement : leçons de la systématique, Journées annuelles de la Société Française de Systématique : systématique et comportement, Paris.

Fureix, C., Hausberger, M., Seneque, E., Morisset, S., Baylac, M., Cornette, R., Biquand, V., Deleporte, P., 2011. Geometric morphometrics as a tool for improving the comparative study of behavioural postures. Naturwissenschaften 98, 583-592.

Fureix, C., Jego, P., Henry, S., Lansade, L., Hausberger, M., 2012. Towards an ethological animal model of depression? A study on horses. PloS one 7, e39280.

Gregoire, J., Bergeron, R., D'Allaire, S., Meunier-Salaün, M.C., Devillers, N., 2013. Assessment of lameness in sows using gait, footprints, postural behaviour and foot lesion analysis. Anim. 7, 1163-1173.

Herskin, M.S., Jensen, K.H., 2000. Effects of different degrees of social isolation on the behaviour of weaned piglets kept for experimental purposes. Anim. Welfare 9, 237-249.

Hörning, B., 2007. 19. Space allowance, in: Velarde, A., Geers, R. (Eds.), On farm monitoring of pig welfare, Wageningen Academic Publishers, Wageningen, The Netherlands, pp. 121-126.

Kanitz, E., Hameister, T., Tuchscherer, M., Tuchscherer, A., Puppe, B., 2014. Social support attenuates the adverse consequences of social deprivation stress in domestic piglets. Horm. Behav. 65, 203-210. 
Kiley-Worthington, M., 1976. The tail of ungulates, canids, and felids with particular reference to their causation and function as displays. Behav. LVI, 69-115.

Lepicard, E.M., Venault, P., Negroni, J., Perez-Diaz, F., Joubert, C., Nosten-Bertrand, M., Berthoz, A., Chapouthier, G., 2003. Posture and balance responses to a sensory challenge are related to anxiety in mice. Psych. Res. 118, 273-284.

Lepicard, E.M., Venault, P., Perez-Diaz, F., Joubert, C., Berthoz, A., Chapouthier, G., 2000. Balance control and posture differences in the anxious BALB/cByJ mice compared to the non anxious C57BL/6J mice. Behav. Brain Res. 117, 185-195.

Lesimple, C., Fureix, C., De Margerie, E., Seneque, E., Menguy, H., Hausberger, M., 2012. Towards a Postural Indicator of Back Pain in Horses (Equus caballus). PloS one 7(9): e44604. doi:10.1371/journal.pone.0044604.

Murphy, E., Nordquist, R.E., van der Staay, F.J., 2014. A review of behavioural methods to study emotion and mood in pigs, Sus scrofa. App. Anim. Behav. Sci. 159, 9-28.

Poursaberi, A., Bahr, C., Pluk, A., Van Nuffel, A., Berckmans, D., 2010. Real-time automatic lameness detection based on back posture extraction in dairy cattle: Shape analysis of cow with image processing techniques. Computers and Electronics in Agriculture 74, 110119.

Reimert, I., Bolhuis, J.E., Kemp, B., Rodenburg, T.B., 2013. Indicators of positive and negative emotions and emotional contagion in pigs. Physiol. Behav. 109, 42-50.

Sather, A.P., Fredeen, H.T., 1982. The effect of confinement housing upon the incidence of leg weakness in swine. Can. J. Anim. Sci., 62, 1119-1128. 
Schenck, E. L.; McMunn, K. A.; Rosenstein, D. S., Stroshine RL, Nielsen BD, Richert BT, Marchant-Forde JN, Lay DC, 2008. Exercising stallhoused gestating gilts: effects on lameness, the musculo-skeletal system, production, and behavior. J. Anim. Sci., 86, 3166-3180. $\quad$ Schilder,

M.B.H., van der Borg, J.A.M., 2004. Training dogs with help of the shock collar: short and long term behavioural effects. App. Anim.

Behav. Sci. 85, 319-334.

Stavrakakis, S., Guy, J.H., Warlow, O.M.E., Johnson, G.R., Edwards, S.A., 2014. Walking kinematics of growing pigs associated with differences in musculoskeletal conformation, subjective gait score and osteochondrosis. Livestock Sci. 165, $104-113$.

Tallet, C., Linhart, P., Policht, R., Hammerschmidt, K., Simecek, P., Kratinova, P., Spinka, M., 2013. Encoding of Situations in the Vocal Repertoire of Piglets (Sus scrofa): A Comparison of Discrete and Graded Classifications. PloS one 8(8): 1932-6203). doi: e7184110.1371/journal.pone.0071841.

Tallet, C., Sy, K., Prunier, A., Nowak, R., Boissy, A., Boivin, X., 2014. Behavioural and physiological reactions of piglets to gentle tactile interactions vary according to their previous experience with humans. Livestock Sci 167, 331-341.

Tuchscherer, M., Kanitz, E., Puppe, B., Hameister, T., Tuchscherer, A., 2014. Social support modulates splenocyte glucocorticoid sensitivity in piglets exposed to social deprivation stress. Physiol. Behav. 131, 25-32.

Vermeer, H.M., de Greef, K.H., Houwers, H.W.J., 2014. Space allowance and pen size affect welfare indicators and performance of growing pigs under Comfort Class conditions. Livestock Sci 159, 79-86.

von Wachenfelt, H., Pinzke, S., Nilsson, C., 2009. Gait and force analysis of provoked pig gait on clean and fouled concrete surfaces. Biosys. Eng. 104, 534-544. 
Weary, D.M., Ross, S., Fraser, D., 1997. Vocalizations by isolated piglets: a reliable indicator of piglet need directed towards the sow. App. Anim. Behav. Sci. 53, 249-257.

Zelditch, M., Swiderski, D., Sheets, H.W.F., 2004. Geometric morphometrics for biologists. A primer. Elsevier Academic Press, San Diego. 
Figure captions

Figure 1. Schematic representation of the testing area.

Figure 2. Landmarks for posture evaluation.

Figure 3. Changes in the number of animals (a) approaching the human when she/he entered the pen, (b) keeping contact with the human during the session, (c) following the human when she/he left the pen. $\mathrm{GH}=$ group-housed animals $(\mathrm{N}=24)$, IH = individually-housed animals $(\mathrm{N}$ $=$ 24), * $=P<0.05$ between $\mathrm{GH}$ and IH (Fisher's exact test).

Figure 4. Results of the first two dimensions of the Principal Components Analysis performed on the behavioural reactions to the testing conditions, novel and habituation. (a) Variables (voc = vocalisations). (b) Individuals. Individually-housed animals in novel condition (Inovel, first day of test), and habituation conditions (Ihab, fourth-fifth day of test), Group-housed animals in novel (Gnovel), and habituation (Ghab) conditions. 
Figure 5. The first two dimensions of the Principal Components Analysis of the shape coordinates of the individually (I) and group-housed (G) animals observed in novel and habituation conditions. (a) Individuals, each represented by a point (labels and colours as in Figure 4b). (b) Schematic representation of the shape at the extremities of dimension 1 (grey dotted lines) and pictures of animals with extreme positions on the axis. The mean shape is represented by red points. Arrows represent distortions compared to the mean. (c) Similarly for dimension 2.

Figure 6. Representation of individuals according to rearing conditions and time in contact with the experimenter, for the Principal Components Analysis of the shape coordinates. Quartile 1: animals that spent less time in contact than the first quartile; quartile 3: animals that spent more time than the third quartile. 
Tables

Table 1. Timeline of the experiment

\begin{tabular}{|c|c|c|c|c|}
\hline Week & Day & Event / observation & Place & Measures \\
\hline \multirow{3}{*}{1} & 1 & Moving to the finishing room & & \\
\hline & & One session of handling & & \\
\hline & $2-5$ & Two sessions of handling per day & Rearing pen & Behaviour \\
\hline \multirow{4}{*}{2} & & One session of handling per day & & \\
\hline & $8-12$ & $\begin{array}{l}\text { Habituation to being marked by a coloured } \\
\text { marker on the back }\end{array}$ & Rearing pen & Behaviour \\
\hline & & Habituation to salivary sampling & & \\
\hline & 12 & Salivary sampling at $08: 00$ and $16: 00 \mathrm{~h}$ & Rearing pen & Cortisol level \\
\hline \multirow{4}{*}{3} & 15 & Isolation in an unfamiliar corridor & Testing pen & Behaviour and posture \\
\hline & $16-17$ & Isolation in the same corridor & Testing pen & - \\
\hline & $18-19$ & Isolation in the same corridor & Testing pen & Behaviour and posture \\
\hline & 20 & Video recordings from $11: 00$ to $13: 00 \mathrm{~h}$ & Rearing pen & General activity \\
\hline 4 & $22-23$ & $\begin{array}{l}\text { Presence in the same corridor with an } \\
\text { experimenter }\end{array}$ & Testing pen & Behaviour and posture \\
\hline
\end{tabular}




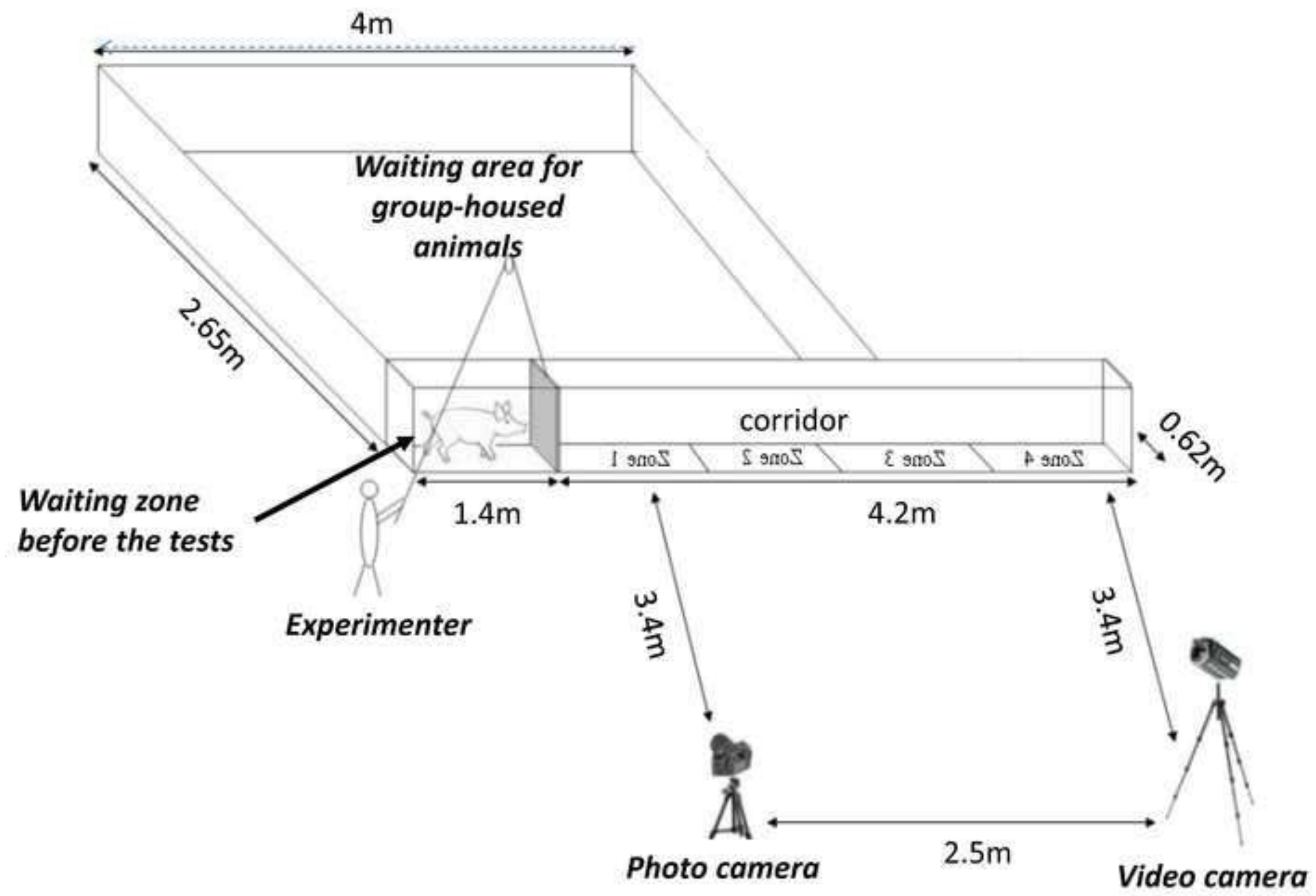




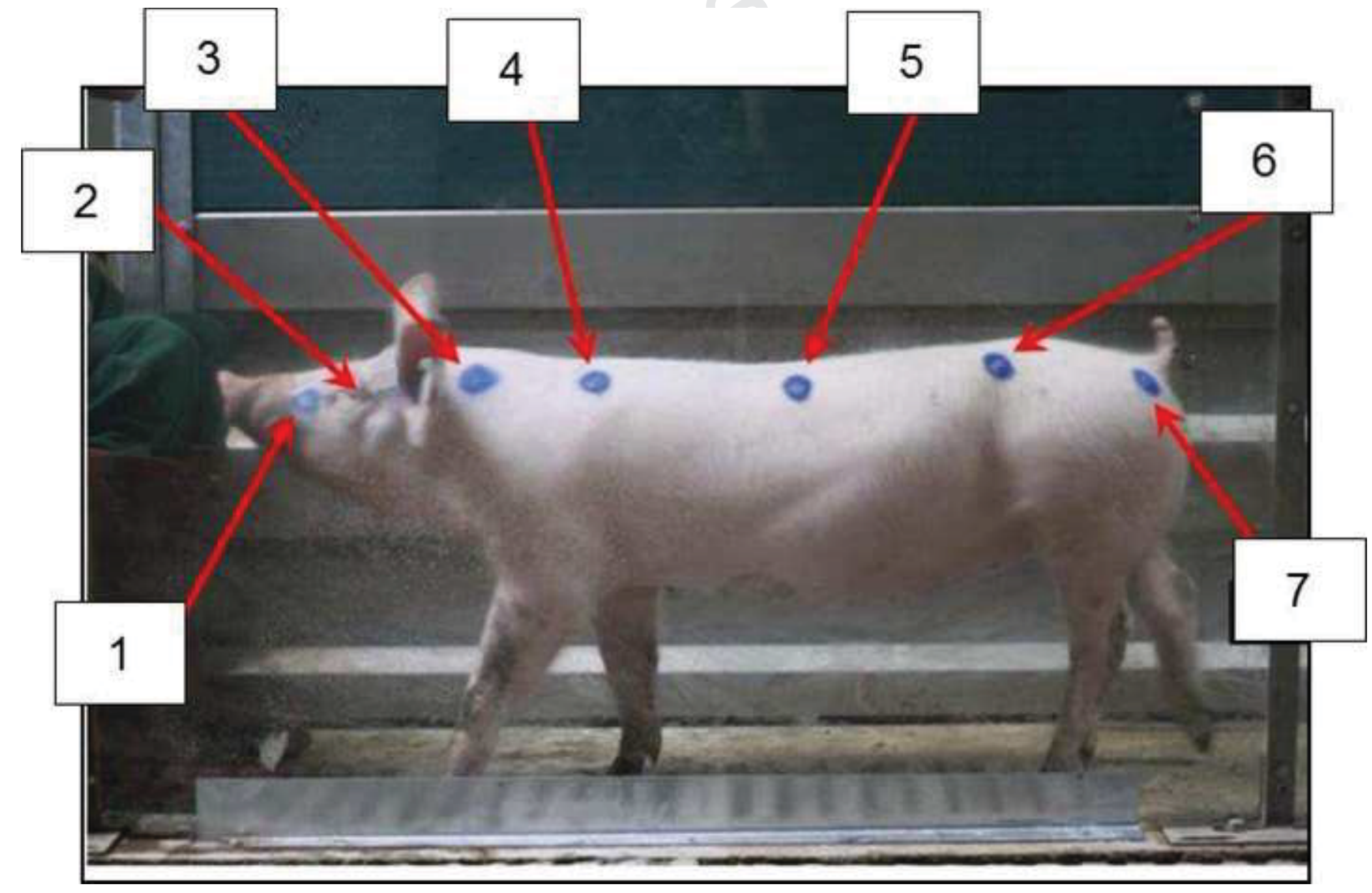


(a) At human entry

Number of pigs approaching

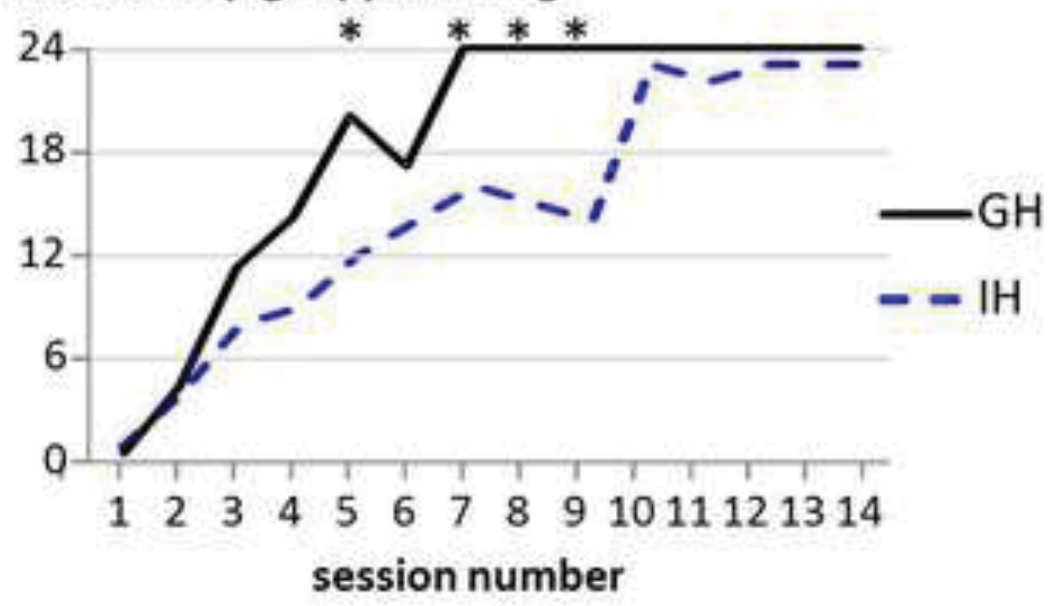

(b) During contact

Number of pigs staying in contact

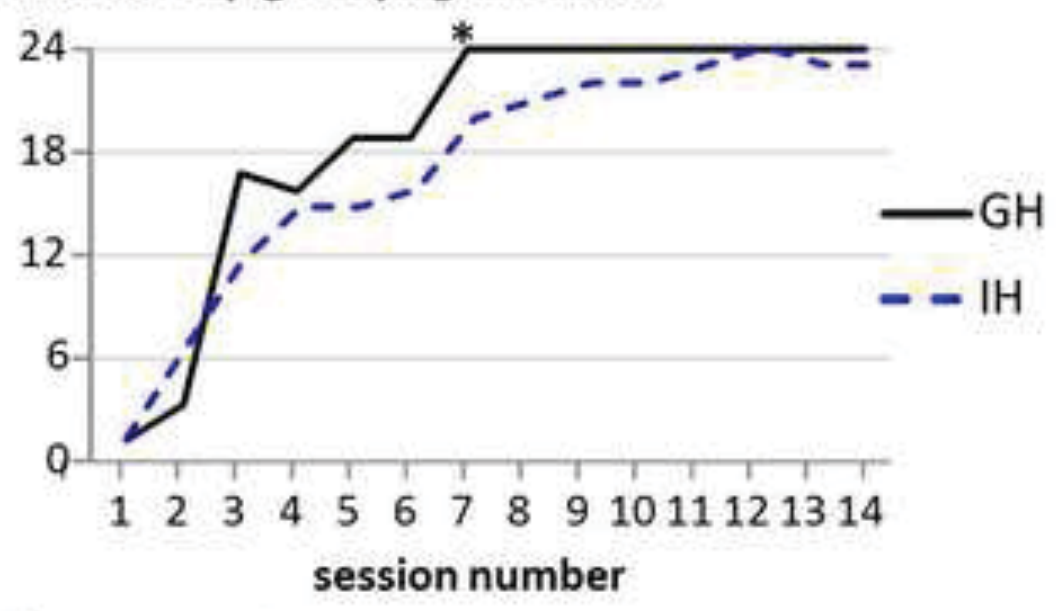

(c) At human exit

Number of pigs following

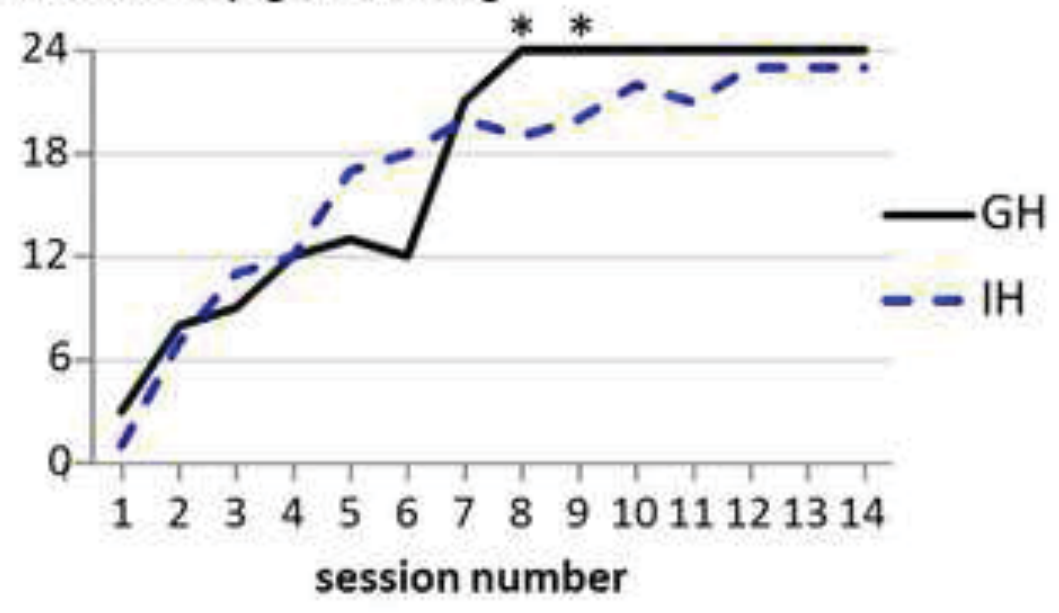


(a)

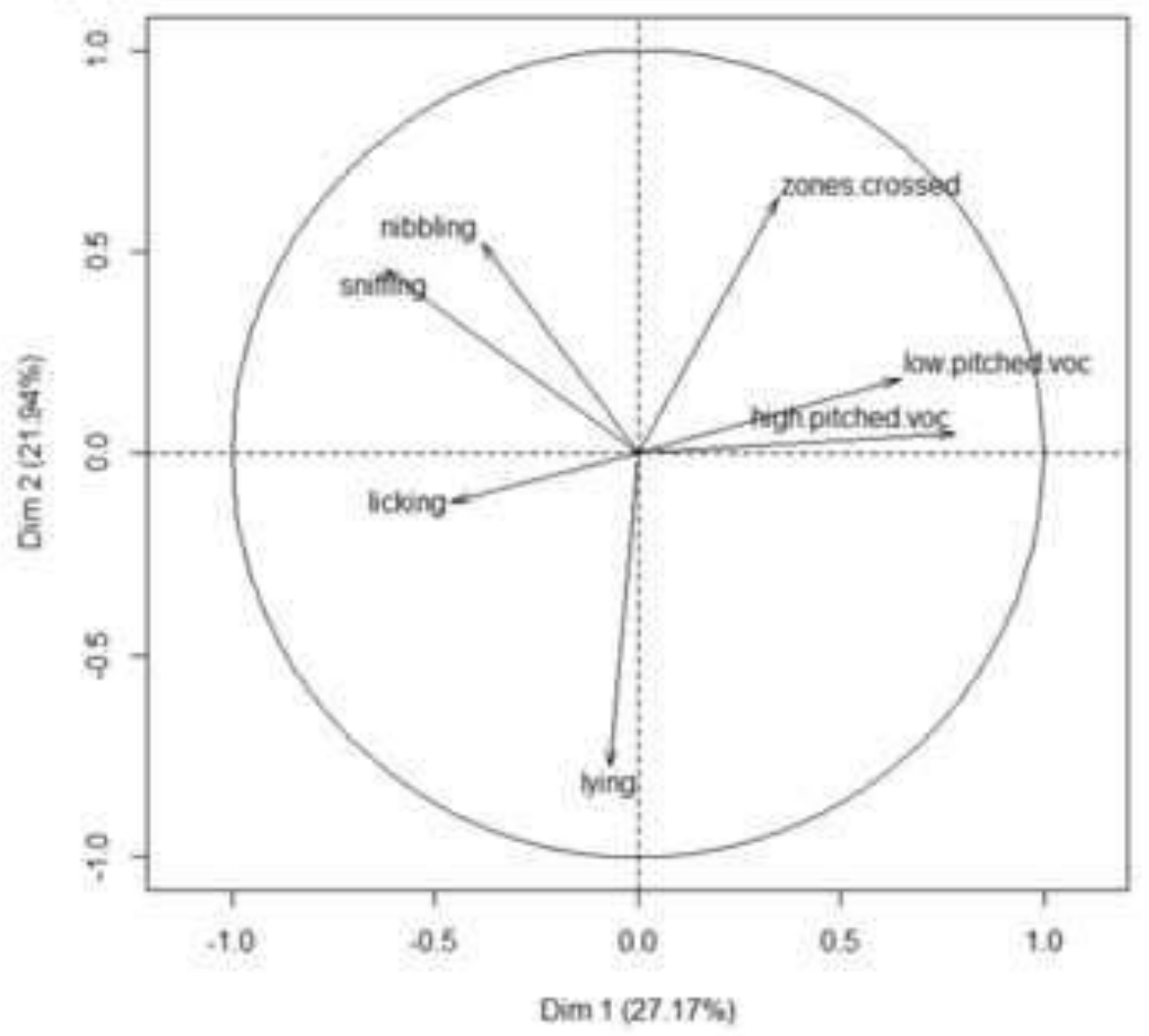

(b)

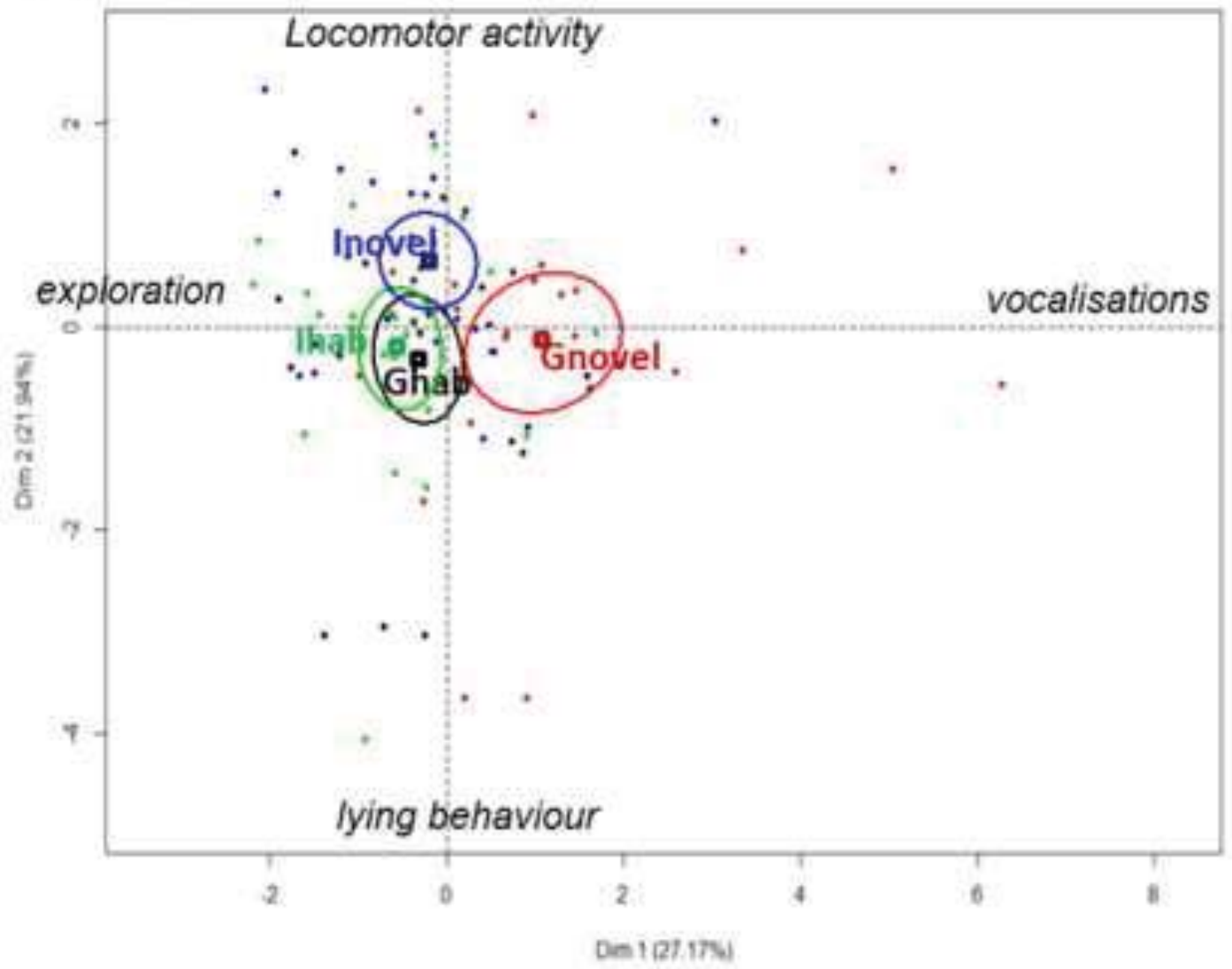


(a) individuals represented on the PCA graph

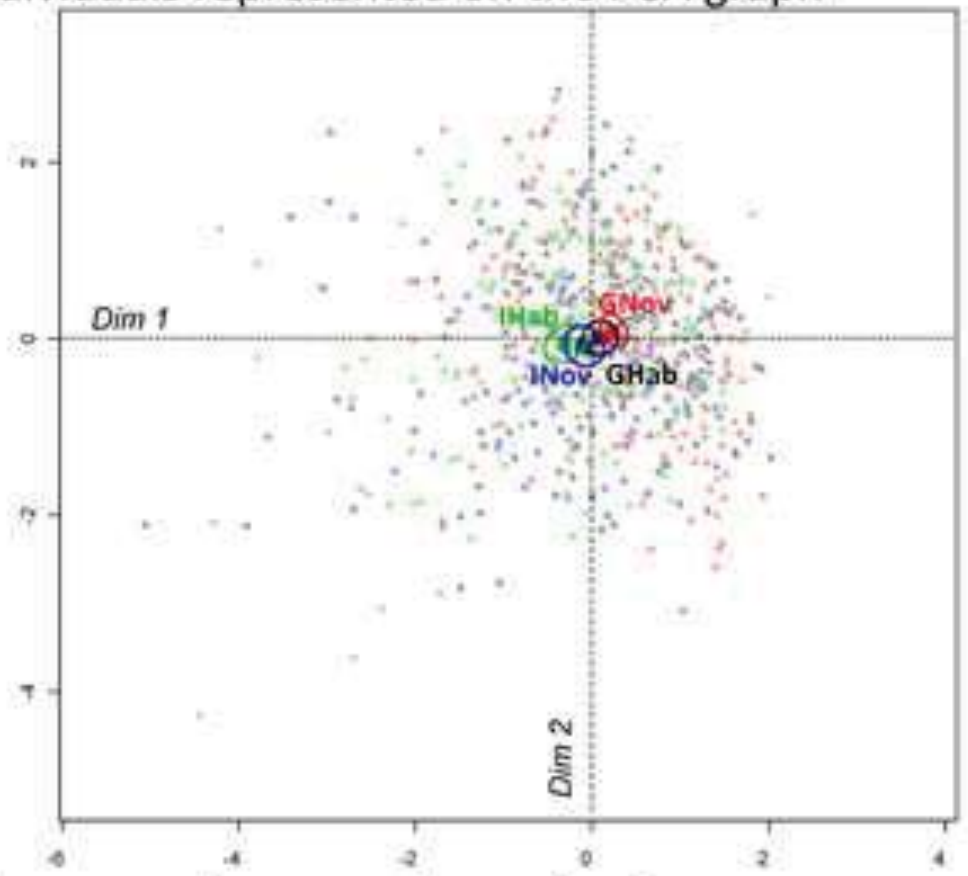

(b) extreme postures on dimension 1
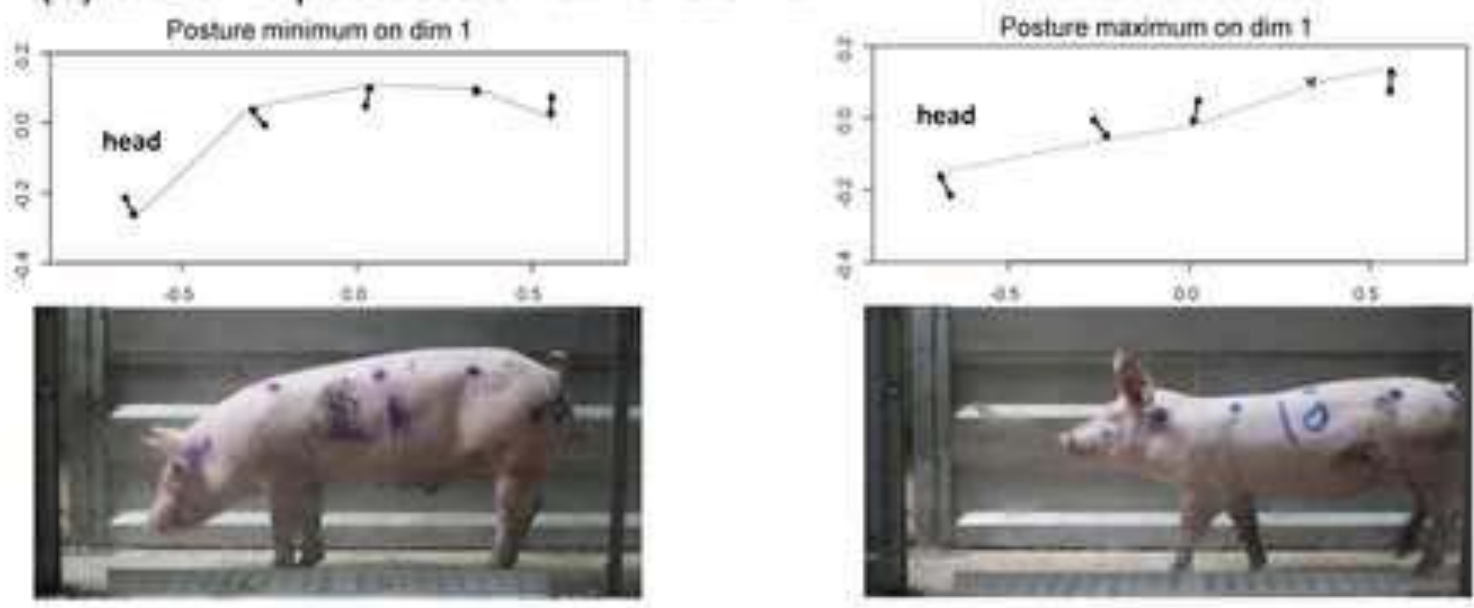

(c) extreme postures on dimension 2
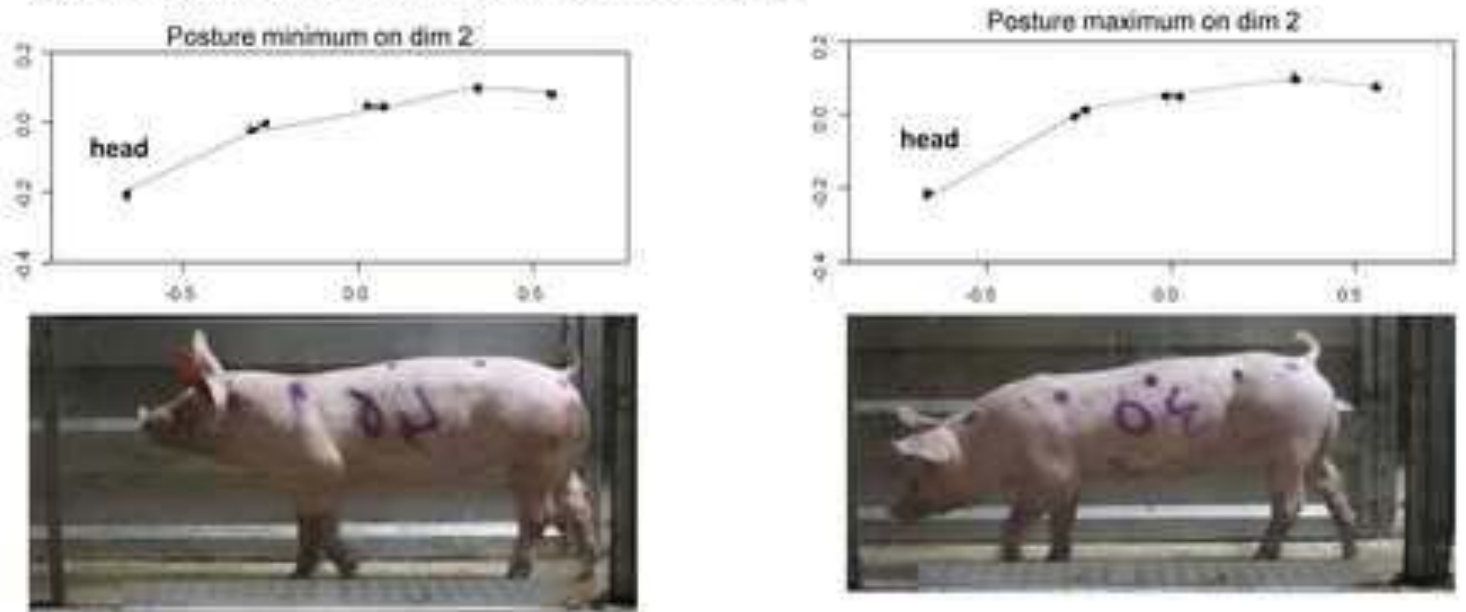


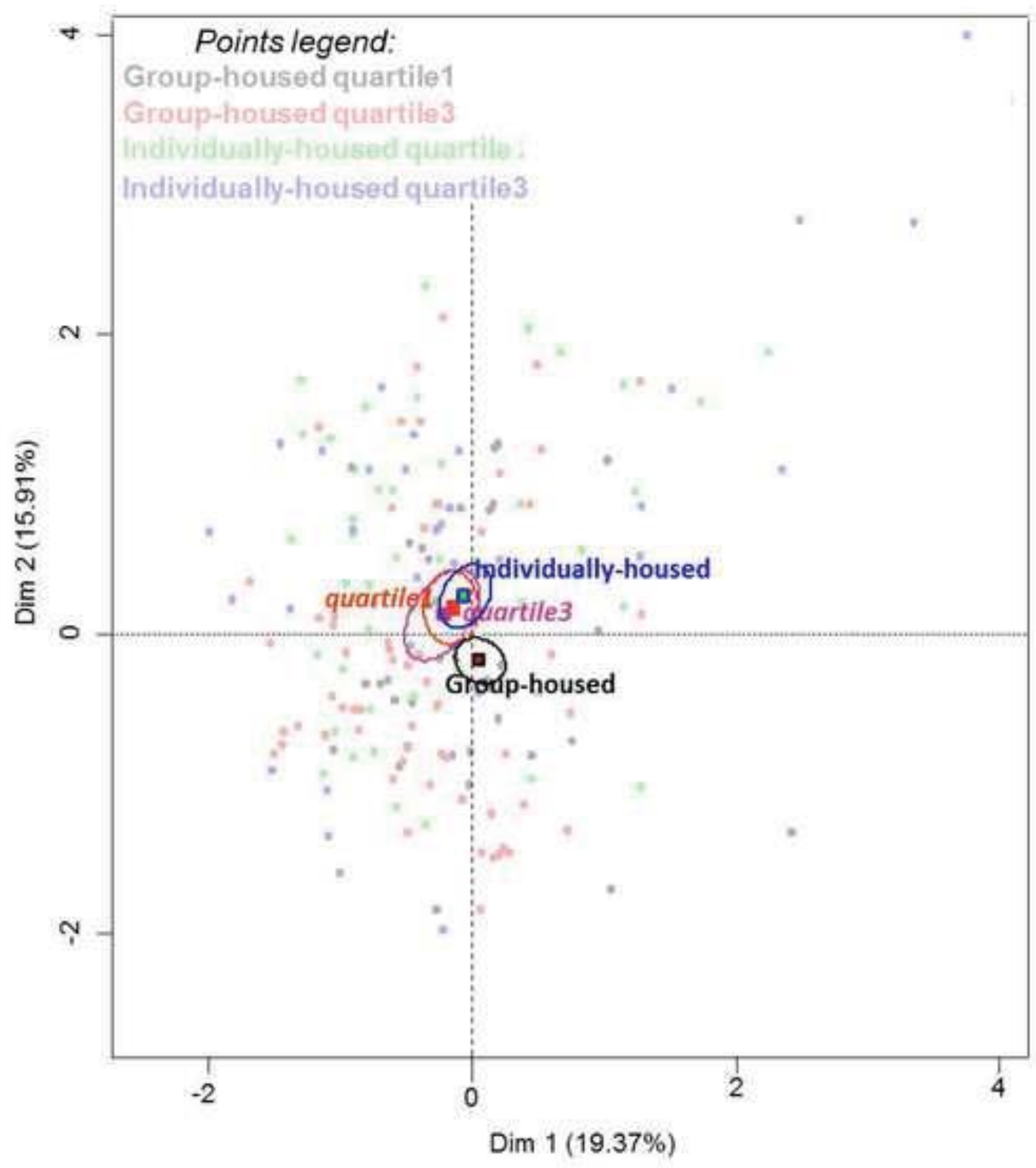

